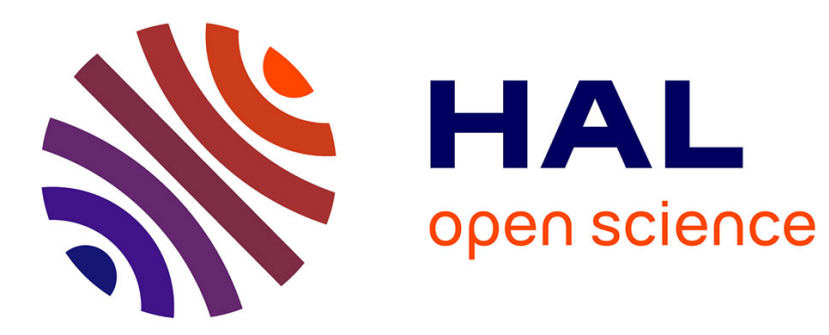

\title{
SCATTERING BY A SEMI-INFINITE ELASTIC PLATE IMMERSED IN WATER
}

M. Ech-Cherif El-Kettani, P. Pareige, F. Luppe

\section{To cite this version:}

M. Ech-Cherif El-Kettani, P. Pareige, F. Luppe. SCATTERING BY A SEMI-INFINITE ELASTIC PLATE IMMERSED IN WATER. Journal de Physique IV Proceedings, 1992, 02 (C1), pp.C1-1015C1-1018. 10.1051/jp4:19921223 . jpa-00251191

\section{HAL Id: jpa-00251191 https://hal.science/jpa-00251191}

Submitted on 1 Jan 1992

HAL is a multi-disciplinary open access archive for the deposit and dissemination of scientific research documents, whether they are published or not. The documents may come from teaching and research institutions in France or abroad, or from public or private research centers.
L'archive ouverte pluridisciplinaire HAL, est destinée au dépôt et à la diffusion de documents scientifiques de niveau recherche, publiés ou non, émanant des établissements d'enseignement et de recherche français ou étrangers, des laboratoires publics ou privés. 


\title{
SCATTERING BY A SEMI-INFINITE ELASTIC PLATE IMMERSED IN WATER
}

\author{
M. ECH-CHERIF EL-KETTANI, P. PAREIGE and F. LUPPE \\ Laboratoire d'Acoustique Ultrasonore et d'Electronique, L.A.U.E.,U.R.A. C.N.R.S. 1373, Place \\ R. Schuman, F-76610 Le Havre, France
}

\begin{abstract}
We present an experimental study of the acoustic scattering by a semi-infinite plate embedded in water, using short pulse signals. The damping coefficient of Lamb modes and their retroreflection coefficient at the extremity of the plate are investigated. The results are presented for four different Lamb modes. We show that the modes with a stronger "transversal" character have a higher retroreflection. coefficient.
\end{abstract}

\section{Introduction}

When an incident short pulse in water strikes a plate at a given incidence angle $\theta$, different Lamb modes are excited. As they propagate along the plate, they radiate energy back in water, under the same angle $\theta$. There is no possibility for mode conversions between different Lamb modes when the plate is an infinite one, unless there exists a discontinuity on its surface. In that case, different modes may be generated when a given one encounters the discontinuity [1]. When a given Lamb mode, generated at a given $\theta$ and a given frequency $f$, reaches the extremity of a semi-infinite plate in water, different phenomena may occur [2]: the conversion of this incident Lamb mode into bulk waves radiated in the surrounding water, its retroreflection, its conversion into bulk longitudinal and shear waves in the plate and into other Lamb modes at the same frequency f. These last modes will propagate in the direction opposite to the one of the incident Lamb wave, and each one will radiate energy back in water under an angle different of $\theta$. A study of the conversion into bulk waves in water is presented in [3]. We are interested here only in the retroreflection of the incident mode.

The experimental set-up is presented in section 2 . The method used for the measurement of the damping and the retroreflection coefficients is described in section 3 , and the results are compared to theoretical ones.

\section{The experimental set-up}

A broadband transducer, of center-frequency $2.25 \mathrm{MHz}$, insonifies a semiinfinite plate of aluminum with short pulses. The plate is embedded in water, its end section has right angles, its thickness is $5 \mathrm{~mm}$. For a given incidence angle $\theta$, different Lamb modes may be excited in the plate at different frequencies included in the frequency bandwidth of the transducer. Each one af these modes is excited with its own amplitude $A^{i n c}$. As a first step, each amplitude $A^{1 n}$ is measured on the resonance spectrum obtained from an experiment of the Snel1-Descartes type (see Fig.1). In the following steps, the experiment is conducted with only one transducer (transducer A of Fig. 1), acting both as an emitter and as a receiver. The acoustic beam of the transducer intersects the plate at angle $\theta$, at a distance $x_{1}$ from the extremity of the plate. The signal 
obtained after reflection at the extremity of the plate is visualized on a numerical oscilloscope which performs the calculation of 1 ts power spectrum. The transducer is then translated in the direction of the $0 \mathrm{x}$. axis by steps of 1 $\mathrm{cm}$, so that the evolution of the amplitude of each Lamb mode with the $x_{1}$ distance may be studied. This study will provide an approximate value for the damping coefficient of each mode, which, in turn, will be used for the determination of the retroreflection coefflcient of that same mode at the extremity of the plate.

\section{Experimental and theoretical results}

We present here the results obtained for four different Lamb modes, generated at an incidence angle $\theta=9^{\circ}$.

\subsection{Kodes identification}

A peak obtained in a power spectrum is associated to a given Lamb mode from the examination of the Lamb modes dispersion curves of the plate. In some cases, however, a peak at a given frequency $f$ and a given angle of excitation $\theta$ may be associated to two different lamb modes. This occurs when two dispersion curves are close from each other. For example, at $\theta=9^{\circ}$ and $f=0.94 \mathrm{MHz}$, we may have excited the $A z$ or the $S_{z}$ mode. After the quthors of reference [4], the resonance width of the $S$ a mode 15 greater than the one of the $A=$ mode. This implies that the experimentally excited mode is $A x$, rather than $S_{2}$.

\subsection{The damping coefficient}

We present a comparison of the experimental and the theoretical values obtained for the damping coefficient of the excited Lamb waves.

3.2.1. Experimental results

When a Lamb wave is excited with an amplitude $A^{\text {inc }}$ at a given incidence angle $\theta$ at a distance $x_{3}$ of the extremity of the plate, it propagates on distance $x_{1}$ and radiates energy back in water under angle $\theta$. After retroreflection at the plate extremity, it propagates once more over the distance $x_{3}$, still radiating energy under angle 8 . The amplitude measured by the transducer $A$ of Fig. 1 . now acting as a receiver is then proportional to:

(1) $A\left(x_{1}\right)=A^{i n t} R \exp \left(-2 \alpha x_{1}\right)$,

where $R$ is the retroreflection coefficient of the mode at the extremity of the plate and $\alpha$ its damping coefficient.

The power spectrum provides :

(2) $20 \log 10\left[A\left(x_{1}\right)\right]=20 \log 10\left[A^{1 m}\right]+20 \log 10 R-40 \alpha x_{1} / \ln 10$.

Fig. 2. shows the plots of 20 log $\left[A\left(x_{1}\right)\right]$ versus $x_{1}$ corresponding to four different Lamb modes excited at $\theta=9^{\circ}$. For each mode, a mean straight line is drawn through the experimental points, the slope of which providing the value of the damping coefficient $\alpha$. The so-obtained values are reported in the third colum of the table of Fig. 3 .

\subsubsection{Theoretical results}

Let us consider a Lamb wave which propagates on an infinite plate embedded in water. Let $V$ be the amplitude of the associated evanescent plane wave in water [6]. At an observation position defined by vector $r$ of coordinates $x_{1}, x_{2}, V$ ls of the form :

(3) $\quad V(r)=V_{0} \exp [-i(\omega t-\mathbf{r} \cdot \mathbf{r})]$,

with $K$ the complex propagation vector defined as :

(4) $\mathbf{K}=\mathbf{K}^{*}+\mathbf{i} \mathbf{K}^{*}$.

Assuming that $K^{\prime}$, and $K^{\prime} \geq$ are the components of the propagation wave-vector $K^{\prime}$ and $K^{\prime \prime}$, and $K^{\prime \prime} z$ the ones of the evanescence wave-vector, it is obvious that $K^{\prime \prime}$, should be identical to the experimentally obtained damping coefficient $\alpha$. The K." 1 value has been calculated for us by $J$. Duclos [5] for the four modes we observed experimentally. These values are given in the fourth column of the table of Fig. 3. One can see from that figure that the experimental values of $\alpha$ 
can be ordered the same way than the theoretical values of $K^{\prime \prime}$,

\subsection{Retroreflection coefficient}

Once $\alpha$ is known, the retroreflection coefficient $R$ may be found out using relation (2), where $A^{\text {*n }}$ is given, for each mode, by the Snell-Descartes experience. The values obtained for the four modes studied are given in ascending order in the third colum of the table of Fig. 4. For a plate embedded in water. it seems reasonable to expect that the modes which have a greater "Iongitudinal" character will radiate more energy in water than those of the "transversal" type which will be more reflected at the extremity of the plate. In order to quantifjy the "Iongitudinal" or "transversal" character of a Lamb wave (which bas an elliptic polarization inside a plate, we used the same parameter m than Viktorov $[6]$ :

$$
m=\int_{-e}^{+e} T_{x_{1} x_{1}}^{2} d x_{2} / \int_{-e}^{+e} T_{x_{1} x_{2}}^{2} d x_{2}
$$

where $T_{m 1 m}$ and $T_{m} 1$ are the components of the stress tensor associated to the incident Lamb wave, so that the value of $\mathrm{m}$ with respect to unity is inaicative of the "longitudinal" or the "transversal" character of the end stress (considered as a whole) associated to the Lamb mode. In other words, the smaller the $m$ parameter is, the larger the retroreflection coefficient should be. This is verfifed by the results indicated on Fig. 4.

\section{Conclusion}

We have presented an experimental method to obtain an estimation of the retroreflection coefficient of Lamb waves at the extremity of a semi-infinite plate embedded in water. For the four modes studied, the values obtained are in a good agreement with the assumption that modes of a more "transversal" type should be more retrareflected at the extremity of the plate than others. We are now using this method far a more exhaustive study of the retroreflection coefficient. This same method is also being extended to allow the study of the conversion of one incident Lamb mode into other lamb modes at the extremity of the plate.

\section{References}

[1] D. C. Gaz1s, R, D. Mindlin, J, Appl. Mech, 27,p541 (1960)

[2] P.J. Torvick, J. Acoust. Soc. Am. 41, p346 (1967)

[3] P.Pareige, F. Luppé, M. Ech-Cherif El-Kettani,J.Ripoche, Zème Congrès Français d'Acoustique, 14-17 Avril 1992, Arcachon, France (this issue)

[4] 0. Lenoir, J.M. Conoir,J,L, Izbicki, 2ème Congrès Français d'Acoustique, 14-17 Avril 1992, Arcachon, France (this issue)

[5] J.Duclos, O. Lenoir, J.M. Conoir, J.L. Izbicki, 2ème Congrès Français d'Acoust1que, 14-17 Avril 1992, Arcachon, France (this issue)

[6] I.A.Viktorov, "Rayleigh and Lamb waves, Physical Theory and Applications", Plenum Press, New-York (1967) 


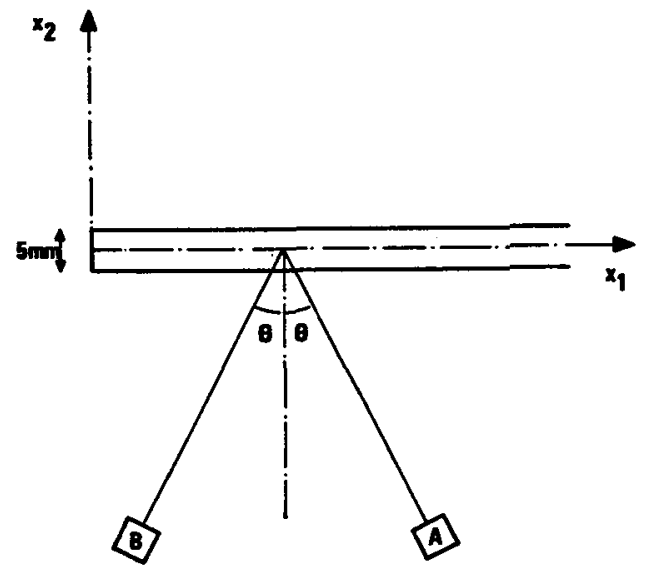

Fig. 1: Experimental geometry. The transducer B is used only for the Snell-Descartes experiment.

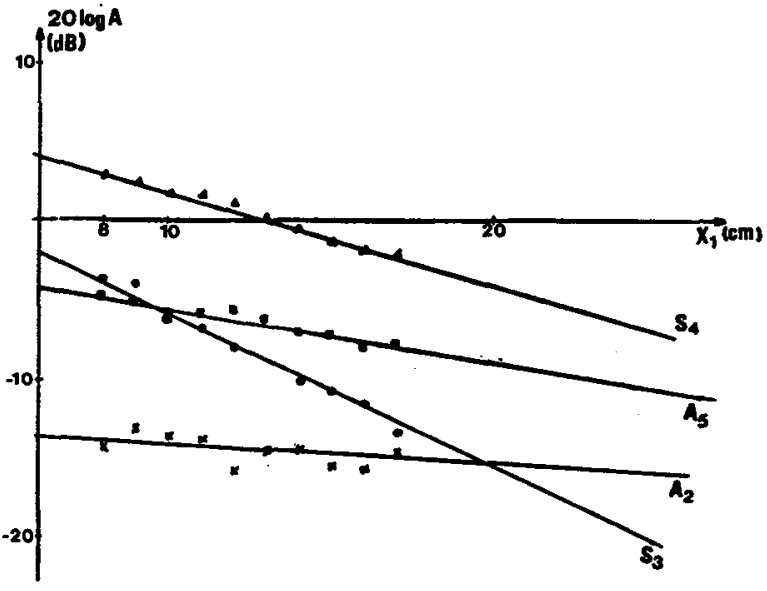

F18.2: Attenuation curres of the Lamb nodes studied.

Fig. 3: Theoretical and experimental values of the damping coefficient.

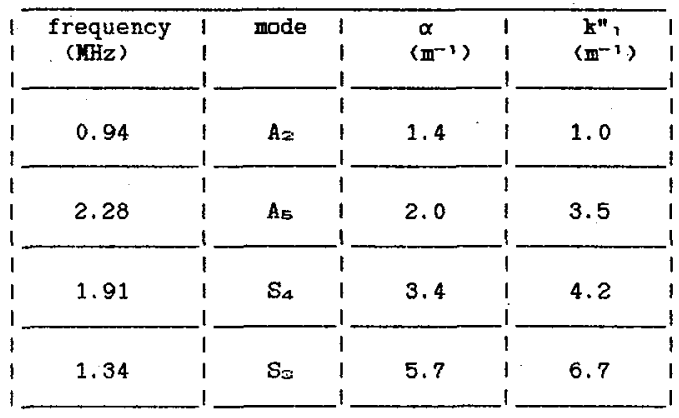

Fig. 4: Values of the experimental retroreflection coefficient $R$ and the Viltorov's parameter II

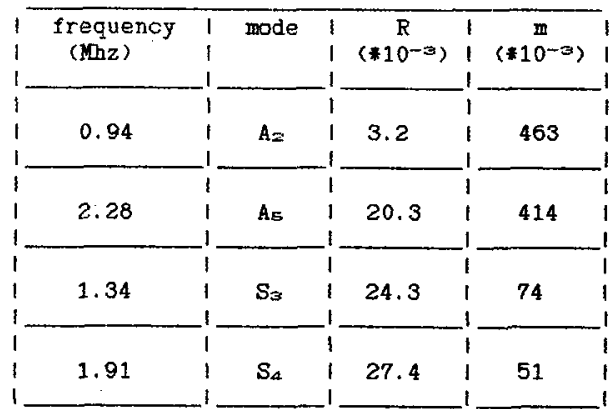

